\title{
ANTIMUTAGENIC POTENTIAL OF LIV52 BY AMES SALMONELLA/MAMMALIAN: MICROSOME MUTAGENICITY ASSAY
}

\author{
RADHAKRISHNA $\mathbf{M}^{1 *}$, HEDGE MJ ${ }^{2}$ \\ ${ }^{1}$ Department of Microbiology, Kasturba Medical College, Mangalore, Manipal University Karnataka, India. ${ }^{2}$ Department of Biosciences, \\ Mangalore University, Mangalagangotri, Karnataka, India. Email: manipuraradhakrishna@yahoo.com
}

Received: 13 November 2016, Revised and Accepted: 23 November 2016

\begin{abstract}
Objective: Liv52, a nontoxic herbal preparation is reported to be clinically active in hepatotoxicity and a wide range of hepatic disorders. This study was undertaken to evaluate the mutagenic/antimutagenic potential of Liv52 using Salmonella mutagenicity test.

Methods: Ames Salmonella/Mammalian - microsome mutagenicity test was used to evaluate the mutagenic or antimutagenic potential of Liv52. Salmonella typhimurium tester strains TA1537, TA1538, TA100, and TA102 were used for mutagenicity testing. The antimutagenicity study was carried out in tester strains TA1538 and TA100 against various standard mutagens with and without metabolic activation

Results: Liv52 did not show any mutagenic potential both with and without metabolic activation, whereas in TA1538 and TA 100 tester strains, Liv52 showed $48.4 \%$ and $47.2 \%$ of inhibition of his ${ }^{+}$revertants induced by 4-nitro-0-phenylenediamine, respectively. Further with metabolic activation in TA1538, Liv52 showed 99.8\%, 99.8\%, and 100\% inhibition of his ${ }^{+}$revertants induced by 2-aminofluorene, 2 -anthranine, and cigarette smoke condensate, respectively. In TA100 maximum of $100 \%, 100 \%, 97.7 \%$, and $100 \%$ inhibition of his ${ }^{+}$revertants induced by 2 -aminofluorene, 2 -anthranine, benzo(a)pyrene, and cigarette smoke condensate, respectively, were observed. A significant enhancement of inhibition of his ${ }^{+}$revertants induced by
\end{abstract} all the above said mutagens were observed in preincubation modification method.

Conclusion: Liv52 was found to be nonmutagenic in Salmonella assay, whereas manifested the antimutagenic potential both with and without metabolic activation. The enhanced antimutagenic activity of Liv52 on preincubation indicates that the antimutagenic factor(s) may be desmutagenic in nature. The exact mechanism by which Liv52 exerts antimutagenic potential is not known. The possibility of having diverse antimutagenic factors in Liv52 which act by different mechanisms are strongly indicated.

Keywords: Liv52 syrup, Salmonella mutagenicity test, Ames test, Desmutagens.

(C) 2017 The Authors. Published by Innovare Academic Sciences Pvt Ltd. This is an open access article under the CC BY license (http://creativecommons. org/licenses/by/4. 0/) DOI: http://dx.doi.org/10.22159/ajpcr.2017.v10i3.16148

\section{INTRODUCTION}

The phytochemicals are secondary metabolic products produced by plants in response to environmental stresses. Thousands of these phytochemicals have been identified and when consumed in human diet, may affect chronic disease risk. Of well over 2000 preparations known to the modern practitioner of Ayurveda, nearly 1500 are of plant origin [1]. Susruta Samhita refers to 700 drugs including a small number, which were not available in the country in that time. India has been exposed for well over a century to the application of allopathic medicines with their definite merits as well as failings.

The studies carried out on antimutagenic effects of the ayurvedic therapies were critically reviewed, their protocol studied, and the significant results have been pointed out as this effect may account for their therapeutic effect to great extent [2]. The ayurvedic herbs have antimutagenic and antiviral activity occupy an important place in the ayurvedic system of medicine and are used in the treatment of various ailments either alone or from a part of various formulations [3]

The mutagenicity refers to the induction of permanent transmissible changes in the structure of genetic material within cells and organisms [4,5]. The mutations are caused by mutagens such as reactive oxygen species (ROS), ultraviolet radiation, ionizing radiation, pollution, and are also the end products of normal metabolic processes of aerobic organisms [6-8]. Oxidative stress caused by ROS is known to cause tissue injury and can include damage to DNA, proteins, and lipids $[9,10]$. Oxidative injury to DNA occurs when oxygen radicals react with DNA [6]. If not repaired, the changes in nucleic acid bases and the breaks in the DNA chain that occur after free radical reactions lead to DNA mutation and mutagenic forms of DNA $[4,10]$

The term genotoxicity is a broader concept than mutagenicity and describes the capacity of the compounds to affect the DNA structure or the cellular apparatus and topoisomerases, which are responsible for the genome fidelity. Genotoxic effects on DNA are not always related to mutations $[11,12]$. The mutations are created mainly by external factors, including chemical and physical agents, called mutagens. In addition, the mutations can occur spontaneously due to errors in DNA replication, repair, and recombination. In general, mutations can be grouped into negative, neutral, positive, lethal, and sublethal The mutagenic changes that occur in germline cells can be passed to future generations, whereas somatic mutations may contribute to the pathogenesis of various pathological conditions, including cancer [13-16].

Antimutagenic agents are able to counteract the effects of mutagens Therefore, knowledge on the mode of action of certain mutagenic compounds provides a basis for an explanation of how antimutagenic compounds work. Identifying the antimutagenic compounds are among the most promising areas of research in recent years [17]. In this study, the mutagenic and antimutagenic potential of Liv52 was evaluated by employing Salmonella mutagenicity test with and without metabolic activation. 


\section{MATERIALS AND METHODS}

\section{Materials}

Liv52 syrup

Liv52 syrup is a patented product of Himalaya drugs and Co. India comprising a standardized mixture of the plants Capparis spinosa (13.6 $\mathrm{mg} / \mathrm{ml})$, Cichorium intybus $(13.6 \mathrm{mg} / \mathrm{ml})$, Solanum nigrum (6.4 $\mathrm{mg} / \mathrm{ml})$, Terminalia arjuna $(6.4 \mathrm{mg} / \mathrm{ml})$, Cassia occidentalis $(3.2 \mathrm{mg} / \mathrm{ml})$, Achillea millefolium $(3.2 \mathrm{mg} / \mathrm{ml})$, and Tamarix gallica $(3.2 \mathrm{mg} / \mathrm{ml})$.

\section{Chemicals}

Nutrient broth and agar were purchased from HiMedia Laboratories Pvt. Ltd. 2-aminofluorene(2-AF), 2-anthranine (2-AN), benzo(a)pyrene $(\mathrm{B}(\mathrm{a}) \mathrm{P}), 4$-nitro-0-phenylenediamine (NPD), butylated hydroxyanisole (BHA), D L $\alpha$ tocopherol (Vitamin E), $\beta$ naphthoflavone, phenobarbitone sodium, cumene hydroperoxide, 2-aminoacridine, dantron, D-biotin, and L-histidine were purchased from Sigma Chemical Company; NADP and glucose 6 phosphate were from Sisco Research Laboratories, India, and Dextrose, $\mathrm{KCl}, \mathrm{MgCl}$, and other buffer components were from SD Fine Chemicals, India. 2

\section{Salmonella tester strains and mutagenicity test}

Salmonella typhimurium tester strains TA1537, TA1538, TA100, and TA102 were kindly supplied from Bruce N Ames Laboratory, University of California, USA. An optimum association of standard tester strains for maximum detection of mutagens was used in this study [18]. The plate incorporation and preincubation modification method using tester strains with and without metabolic activation were carried out essentially [19].

\section{Metabolic activation}

Rat liver S9 fraction was used where induction of liver enzymes was done using phenobarbitone and beta-naphthoflavone [20,21]. S9 mixture was prepared freshly before the test by adding cofactors $(8 \mathrm{~mm}$ $\mathrm{MgCl}, 33 \mathrm{~mm} \mathrm{KCl}, 5 \mathrm{~mm}$ glucose 6 phosphate, and $4 \mathrm{~mm}$ NADP at the $\mathrm{pH}{ }^{2} .4$ ) to $50 \mu \mathrm{l}$ of S9 [19].

\section{Methods}

Ames Salmonella/mammalian - microsome mutagenicity test (an in vitro short-term mutagenicity test) was used in this study. S. typhimurium tester strains TA1537, TA1538, TA100, and TA102 were used for mutagenicity testing. The antimutagenicity study was conducted using tester strains TA1538 and TA100 against various standard mutagens with and without metabolic activation.

\section{Mutagenicity assay}

All the tester strains of $S$. typhimurium were analyzed for mutagenicity assay with and without S9 mix. The molten soft agar of $2 \mathrm{ml}$, various concentrations of the test compound (10 to $500 \mu \mathrm{l}$ ) of Liv52, $0.1 \mathrm{ml}$ of overnight bacterial culture, and $0.5 \mathrm{ml}$ of S9 mix (wherever used) were added, gently mixed and poured over minimal glucose agar medium and incubated at $37^{\circ} \mathrm{C}$ for $48 \mathrm{hrs}$. After incubation, the plates were counted for his ${ }^{+}$revertants. The experiment was performed in duplicate using the similar procedure for all the concentrations. The results were determined as mean of six plates per point with standard deviation and viable cell count as approximately $1-2 \times$ $10^{9} \mathrm{cfu} / \mathrm{ml}$. The positive mutagenic controls including 4-Nitro-Ophenylenediamine (-S9) for TA1538 and TA100; aminoacridine (-S9) for TA1537; cumene hydroperoxide (-S9) for TA102, 2-aminofluorne, 2-antramine, and Benzo(a)pyrene $(+S 9)$ for TA1538 and TA100, Emodin (+S9) for TA1537, and dantron (+S9) for TA102 were used. All the solutions were prepared freshly by dissolving in dimethyl sulfoxide.

\section{Antimutagenicity assay}

For antimutagenicity assay, plate incorporation method and preincubation method were used by incorporating the tester strains TA1538 and TA100. For plate incorporation assay to $2 \mathrm{ml}$ of the molten soft agar various concentrations of test compound (10 to $500 \mu \mathrm{l}$ ), $0.1 \mathrm{ml}$ of overnight bacterial culture, $0.1 \mathrm{ml}$ of known appropriate positive mutagen control, and $0.5 \mathrm{ml}$ of $\mathrm{S} 9 \mathrm{mix}$ (wherever used) were added aseptically and poured over minimal glucose agar medium and incubated at $37^{\circ} \mathrm{C}$ for 48 hrs. For antimutagen control, BHA and Dl tocopherol were used.

For preincubation method, $0.1 \mathrm{ml}$ of overnight culture, various concentrations of test compounds, optimal concentration of appropriate known mutagen control, and $0.5 \mathrm{ml}$ of $\mathrm{S} 9 \mathrm{mix}$ were added in sterile tubes, mixed thoroughly using vortex mixture and incubated at $37^{\circ} \mathrm{C}$ for 20-30 minutes. This mixture was added to molten top agar and poured on the surface of minimal glucose agar and continued further as in plate incorporation method. The results were expressed as the mean of six plates from two independent experiments with standard deviation. Antimutagenicity or percentage of inhibition of mutagenicity by Liv52 was calculated using formula as given below.

Antimutagenicity/percentage of inhibition of mutagenicity $=(a-b) /$ $(a-c) \times 100$

Where,

$\mathrm{a}=$ number of his ${ }^{+}$revertants induced by positive mutagen,

$\mathrm{b}=$ number of his $^{+}$revertants induced by the positive mutagen in the presence of test Compound, $\mathrm{c}=$ number of his ${ }^{+}$revertants induced by the test compound alone.

\section{Statistical evaluation}

Statistical analysis was performed using Karl Pearson Correlation Coefficient method. Statistical Package for the Social Sciences (SPSS) ver.15.0 was used.

\section{RESULTS AND DISCUSSION}

The present investigation depicts the antimutagenic potential of various concentrations of Liv52 in S. typhimurium reverse mutation assay. The test preparation was found to be nontoxic to the tester strains at different doses with or without metabolic activation. The characteristics his ${ }^{+}$revertants patterns of the standard tester strains to various standard mutagens were shown in Table 1 . The viable count was approximately $1-2 \times 10^{9}$ cells $/ \mathrm{ml}$ in all the tester strains (TA1537, TA1538, TA100, and TA102).

Liv52 failed to induce his $^{+}$revertants in all the four tester strains either in the presence or absence of metabolic activation by plate incorporation method thereby found to be nonmutagenic in Ames test (Table 2).

The effect of Liv52 on NPD induced mutation frequency by plate incorporation method was depicted in Table 3 . It was very clearly defined and proved that Liv52 inhibited NPD induced his $^{+}$revertants significantly in both the strains that were dose-dependent. In TA1538, the highest inhibitory effect was $48.4 \%$ and in TA100 it was $47.2 \%$ at the dose of $100 \mu$ l of Liv52 per plate.

Fig. 1 Highlighted the effects of Liv52 on NPD induced mutation frequency in TA1538 and TA100 by preincubation method. Further, there was a significant enhanced inhibitory effect on preincubation (63.1\% in TA1538 and 61.8\% in TA100).

The effect of Liv52 on 2-aminofluorene, 2-anthramine, and cigarette smoke condensate-induced mutation frequency in TA1538 by plate incorporation method was well defined in this study (Table 4). From these data, it was obvious that in TA1538, Liv52 reduced his ${ }^{+}$revertants induced by the above said indirect mutagens, in a dose-dependent manner. At a dose of $100 \mu \mathrm{l}$ of Liv52 per plate, the percentage inhibitions of his ${ }^{+}$revertants were the highest of 99.8 for 2-AF, 99.8 for 2-AN, and 100 for CSC. Further, an increase of the test compound in the bioassay did not make a significant difference in the inhibitory effect (Correlation $\begin{array}{lllll}\text { coefficient } & > & 0.5 & \text { and } & \end{array}$ 
The effect of Liv52 on 2-aminofluorene, 2-anthramine, benzo(a)pyrene, and cigarette smoke condensate-induced mutation frequency in TA100 by plate incorporation method was well defined in this study. From these data, it was obvious that in TA100 also Liv52 reduced his ${ }^{+}$revertants induced by the above said indirect mutagens, in a dose-dependent manner (Correlation coefficient were $>0.5$ and $p<0.005$ ). For the dose of test compound, $100 \mu \mathrm{l}$ per plate the percentage inhibitions of his $^{+}$ revertants were the highest of 100 for 2-AF, 100 for 2-AN, 97.7 for $\mathrm{B}[\mathrm{a}]$ $\mathrm{P}$, and 100 for CSC (Table 5).

Figs. 2 and 3 depict the effect of Liv52 on the above said indirect mutagens induced mutation frequency in TA1538 and TA100, respectively, by preincubation method. It was clear from the figures that there was a significant enhancement in inhibitory action by Liv52 on preincubation (Correlation coefficient was $>0.5$ and $\mathrm{p}<0.005$ ).

\section{DISCUSSION}

Liv52, a polyherbal ayurvedic preparation was found to be nonmutagenic in Ames test. The antimutagenic potential of Liv52 was demonstrated against NPD induced mutagenesis in the absence of metabolic activation in both the tester strains TA1538 and TA100. Liv52 exhibited antimutagenicity against 2-AF, 2-AN, and CSC induced mutagenesis in TA1538 and also against 2-AF, 2-AN, B(a)P, and CSC in TA100 in the presence of metabolic activation. It was evident from the data that the antimutagenic activity of Liv52 was more potent in the presence of metabolic activation than in the absence of $\mathrm{S} 9$ mix (Correlation coefficient was $>0.5$ and $p<0.005$ ). Further, it was noticed that the antimutagenic activity of Liv52 against both direct and S9 dependent mutagens was comparatively more in TA100 than in TA1538. These results indicate that Liv52 inhibits his ${ }^{+}$revertants

Table 1: Characteristic reversion patterns of standard tester strains to diagnostic mutagens

\begin{tabular}{|c|c|c|c|c|c|c|c|c|}
\hline \multirow[t]{3}{*}{ Diagnostic mutagens } & \multicolumn{8}{|c|}{ His $^{+}$revertants/plate } \\
\hline & \multicolumn{2}{|l|}{ TA1537 } & \multicolumn{2}{|l|}{ TA1538 } & \multicolumn{2}{|l|}{ TA100 } & \multicolumn{2}{|l|}{ TA102 } \\
\hline & $-\mathbf{S 9}$ & $+\mathbf{S 9}$ & $-\mathbf{S 9}$ & $+\mathbf{S 9}$ & $-S 9$ & $+\mathbf{+ S 9}$ & $-S 9$ & $+\mathbf{+ S 9}$ \\
\hline Spontaneous revertants & $8 \pm 1$ & $15 \pm 2$ & $15 \pm 1$ & $23 \pm 2$ & $143 \pm 11$ & $161 \pm 9$ & $386 \pm 29$ & $409 \pm 33$ \\
\hline Aminoacridine & $858 \pm 51$ & - & - & - & - & - & - & - \\
\hline Cumene hydroperoxide & - & - & - & - & - & - & $1060 \pm 93$ & - \\
\hline 4-nitro-o- phenylene diamine & - & - & $671 \pm 41$ & - & $539 \pm 31$ & - & - & - \\
\hline Sodium azide & - & - & - & - & $725 \pm 56$ & - & - & - \\
\hline 2-Anthramine & - & $331 \pm 16$ & - & $608 \pm 42$ & - & $721 \pm 50$ & - & - \\
\hline 2-amino fluorine & - & - & - & $633 \pm 39$ & - & $526 \pm 38$ & - & - \\
\hline Benzo (a) pyrene & - & - & - & - & - & $621 \pm 40$ & - & - \\
\hline 7,12-dimethyl benzanthracene & - & - & - & - & - & $783 \pm 56$ & - & - \\
\hline Dantron & - & - & - & - & - & - & - & $1108 \pm 83$ \\
\hline Cigarette smoke condensate & - & - & - & $201 \pm 9$ & - & $433 \pm 26$ & - & - \\
\hline
\end{tabular}

Results were expressed as the mean of six plates from the two independent experiments with standard deviation. Viable cell count was approximately $1-2 \times 10^{9}$ cells $/ \mathrm{ml}$.

Table 2: Nonmutagenicity of Liv52 syrup in tester strains TA1537, TA1538, TA100 and TA102 with and without S9 mix by plate incorporation method

\begin{tabular}{|c|c|c|c|c|c|c|c|c|}
\hline \multirow[t]{2}{*}{ of Liv52 syrup } & \multicolumn{2}{|c|}{ TA1537 } & \multicolumn{2}{|l|}{ TA1538 } & \multicolumn{2}{|l|}{ TA100 } & \multicolumn{2}{|l|}{ TA102 } \\
\hline & $-S 9$ & $+S 9$ & $-S 9$ & $+S 9$ & $-S 9$ & $+S 9$ & $-S 9$ & $+S 9$ \\
\hline Spontaneous revertants & $9 \pm 1$ & $15 \pm 2$ & $13 \pm 2$ & $21 \pm 2$ & $141 \pm 10$ & $158 \pm 12$ & $378 \pm 29$ & $412 \pm 36$ \\
\hline $10 \mu \mathrm{l} /$ plate of Liv52 syrup & $9 \pm 1$ & $13 \pm 1$ & $13 \pm 1$ & $23 \pm 2$ & $129 \pm 10$ & $159 \pm 13$ & $371 \pm 29$ & $408 \pm 29$ \\
\hline $25 \mu \mathrm{l}$ & $12 \pm 1$ & $10 \pm 2$ & $16 \pm 1$ & $21 \pm 1$ & $139 \pm 12$ & $170 \pm 11$ & $385 \pm 35$ & $412 \pm 31$ \\
\hline $50 \mu \mathrm{l}$ & $13 \pm 2$ & $12 \pm 1$ & $21 \pm 2$ & $29 \pm 2$ & $153 \pm 11$ & $149 \pm 10$ & $391 \pm 31$ & $422 \pm 29$ \\
\hline $75 \mu \mathrm{l}$ & $10 \pm 1$ & $18 \pm 2$ & $12 \pm 1$ & $23 \pm 1$ & $133 \pm 9$ & $158 \pm 12$ & $402 \pm 39$ & $410 \pm 51$ \\
\hline $100 \mu \mathrm{l}$ & $9 \pm 1$ & $15 \pm 2$ & $12 \pm 1$ & $19 \pm 1$ & $155 \pm 16$ & $168 \pm 1$ & $394 \pm 29$ & $429 \pm 21$ \\
\hline $200 \mu \mathrm{l}$ & $8 \pm 1$ & $14 \pm 1$ & $23 \pm 2$ & $24 \pm 1$ & $166 \pm 12$ & $148 \pm 9$ & $408 \pm 34$ & $437 \pm 20$ \\
\hline $500 \mu \mathrm{l}$ & $10 \pm 1$ & $10 \pm 1$ & $15 \pm 1$ & $26 \pm 2$ & $143 \pm 11$ & $150 \pm 12$ & $378 \pm 18$ & $426 \pm 16$ \\
\hline
\end{tabular}

Results were expressed as the mean of 6 plates from two independent experiments with standard deviation. Viable cell count was approximately 1-2 $\mathrm{X} 10^{9}$ cells $/ \mathrm{ml}$.

Table 3: Antimutagenicity of Liv52 against NPD induced mutagenesis in TA1538 and TA100 without S9 mix by plate incorporation method

\begin{tabular}{|c|c|c|c|c|}
\hline Various concentrations of Liv52 syrup & TA1538 NPD (5 $\mu \mathrm{g} / \mathrm{plate})$ & $\%$ inhibition & TA100 NPD $(20 \mu \mathrm{g} / \mathrm{plate})$ & $\%$ inhibition \\
\hline Spontaneous revertants & $\begin{array}{l}14 \pm 2 \\
689 \pm 52\end{array}$ & - & $\begin{array}{l}138 \pm 12 \\
541 \pm 51\end{array}$ & - \\
\hline $10 \mu \mathrm{l} /$ plate of Liv52 syrup & $589 \pm 99$ & 14.3 & $491 \pm 43$ & 12.4 \\
\hline $50 \mu \mathrm{l}$ & $364 \pm 31$ & 48.1 & $375 \pm 29$ & 41.2 \\
\hline $75 \mu \mathrm{l}$ & $321 \pm 29$ & 54.4 & $352 \pm 26$ & 46.9 \\
\hline $100 \mu \mathrm{l}$ & $263 \pm 18$ & 63.1 & $292 \pm 21$ & 61.8 \\
\hline $200 \mu \mathrm{l}$ & $271 \pm 19$ & 61.9 & $298 \pm 20$ & 60.3 \\
\hline $500 \mu \mathrm{l}$ & $268 \pm 23$ & 62.4 & $294 \pm 23$ & 61.3 \\
\hline
\end{tabular}

Results were expressed as the mean of 6 plates from two independent experiments with standard deviation. Viable cell count was approximately $1-2$ $\mathrm{X} 10^{9}$ cells $/ \mathrm{ml}$. (Correlation coefficient were $>0.5$ and $\mathrm{p}$ value were $<0.005$ ). 
Table 4: Antimutagenicity of Liv52 syrup against 2-AF, 2-AN, CSC induced mutagenesis in TA1538 with S9 mix by plate incorporation method

\begin{tabular}{|c|c|c|c|c|c|c|}
\hline of Liv52 syrup & 2-AF (5 $\mu$ g/plate) & $\%$ inhibition & 2-AN (1 $\mu \mathrm{g} /$ plate) & $\%$ inhibition & CSC (100 $\mu \mathrm{g} /$ plate $)$ & $\%$ inhibition \\
\hline Spontaneous revertants & $\begin{array}{l}23 \pm 2 \\
612 \pm 51\end{array}$ & - & $\begin{array}{l}25 \pm 2 \\
636 \pm 43\end{array}$ & - & $\begin{array}{l}22 \pm 1 \\
206 \pm 17\end{array}$ & - \\
\hline $10 \mu \mathrm{l} /$ plate of Liv52 syrup & $311 \pm 23$ & 51.1 & $321 \pm 26$ & 51.6 & $127 \pm 9$ & 42.9 \\
\hline $25 \mu \mathrm{l}$ & $162 \pm 11$ & 76.4 & $191 \pm 16$ & 72.8 & $74 \pm 8$ & 71.7 \\
\hline $50 \mu \mathrm{l}$ & $27 \pm 3$ & 99.3 & $52 \pm 6$ & 95.6 & $39 \pm 4$ & 90.8 \\
\hline $75 \mu \mathrm{l}$ & $22 \pm 2$ & 100.2 & $28 \pm 2$ & 99.5 & $24 \pm 3$ & 98.9 \\
\hline $100 \mu \mathrm{l}$ & $23 \pm 1$ & 100 & $24 \pm 2$ & 100.2 & $20 \pm 3$ & 101 \\
\hline Vitamin E $(10 \mu \mathrm{l} /$ plate $)$ & $110 \pm 9$ & 85.2 & $103 \pm 9$ & 87.2 & $51 \pm 6$ & 84.2 \\
\hline BHA (100 $\mu \mathrm{g} /$ plate) & $201 \pm 18$ & 69.8 & $206 \pm 18$ & 70.4 & $86 \pm 9$ & 65.2 \\
\hline
\end{tabular}

Results were expressed as the mean of 6 plates from two independent experiments with standard deviation. Viable cell count was approximately $1-2 \mathrm{X} 10^{9} \mathrm{cells} / \mathrm{ml}$. (Correlation coefficient were $>0.5$ and $\mathrm{p}$ value were $<0.005$ )

Table 5: Antimutagenicity of Liv52 syrup against 2-AF, 2-AN, CSC, and B (a) P induced mutagenesis in TA100 with S9 mix by plate incorporation method

\begin{tabular}{|c|c|c|c|c|c|c|c|c|}
\hline of Liv52 syrup & $\begin{array}{l}2-\mathrm{AF} \\
(10 \mu \mathrm{g} / \text { plate })\end{array}$ & $\begin{array}{l}\% \\
\text { inhibition }\end{array}$ & $\begin{array}{l}2-A N \\
(1 \mu \mathrm{g} / \text { plate })\end{array}$ & $\begin{array}{l}\% \\
\text { inhibition }\end{array}$ & B (a) P $2.5 \mu \mathrm{g} /$ plate & $\begin{array}{l}\% \\
\text { inhibition }\end{array}$ & $\begin{array}{l}\text { CSC } \\
(100 \mu g / \text { plate })\end{array}$ & $\begin{array}{l}\% \\
\text { inhibition }\end{array}$ \\
\hline Spontaneous revertants & $\begin{array}{l}161 \pm 13 \\
525 \pm 13\end{array}$ & - & $\begin{array}{l}159 \pm 14 \\
803 \pm 72\end{array}$ & - & $\begin{array}{l}163 \pm 16 \\
539 \pm 51\end{array}$ & & $\begin{array}{l}165 \pm 12 \\
432 \pm 31\end{array}$ & - \\
\hline $10 \mu \mathrm{l} /$ plate of Liv52 syrup & $299 \pm 16$ & 62.1 & $362 \pm 29$ & 68.5 & $327 \pm 36$ & 56.4 & $295 \pm 20$ & 51.3 \\
\hline $25 \mu \mathrm{l}$ & $192 \pm 21$ & 91.5 & $209 \pm 22$ & 92.2 & $214 \pm 18$ & 86.4 & $226 \pm 29$ & 77.2 \\
\hline $50 \mu \mathrm{l}$ & $170 \pm 13$ & 97.5 & $160 \pm 20$ & 99.8 & $169 \pm 12$ & 98.4 & $175 \pm 19$ & 96.3 \\
\hline $75 \mu \mathrm{l}$ & $160 \pm 11$ & 100.3 & $158 \pm 11$ & 100.2 & $161 \pm 14$ & 100.5 & $160 \pm 23$ & 101.9 \\
\hline $100 \mu \mathrm{l}$ & $158 \pm 16$ & 100.8 & $153 \pm 18$ & 100.9 & $163 \pm 18$ & 100 & $162 \pm 20$ & 100.1 \\
\hline Vitamin E $(20 \mu \mathrm{l} /$ plate $)$ & $161 \pm 14$ & 100 & $173 \pm 21$ & 97.8 & $165 \pm 11$ & 99.5 & $176 \pm 12$ & 95.9 \\
\hline BHA $(100 \mu \mathrm{g} /$ plate $)$ & $263 \pm 23$ & 72 & $292 \pm 26$ & 79.3 & $236 \pm 28$ & 80.6 & $232 \pm 28$ & 74.9 \\
\hline
\end{tabular}

Results were expressed as the mean of 6 plates from two independent experiments with standard deviation. Viable cell count was approximately $1-2 \mathrm{X} 10^{9}$ cells/ml BHA: Butylated hydroxyanisole

arising by base pair substitution more effectively as compared to the frame shift mechanisms.

The exact mechanism, by which Liv52 exerts antimutagenic activity, is not clearly understood. It is a polyherbal formulation with several ingredients. This consistently enhanced activity of antimutagenicity against all the above said mutagens in preincubation studies suggests that the antimutagenic factors may be desmutagenic in nature $[2,22]$. Moreover, Liv52 exhibited antimutagenic activity against various direct and indirect mutagens, and these mutagens bring mutagenesis by different mechanisms, the possibility of having diverse antimutagenic factors which act by different mechanisms on Liv52 is strongly indicated. Thus, due to the proven antioxidant activity of Liv52, it is an important to assess whether the consumption of aqueous extracts of these constituents can assist in the prevention or repair of cellular changes caused by the exposure to potentially mutagenic agents, in addition, to the proven beneficial effects for health and well-being. The protective effect of aqueous extracts of any medicinal products was determined by testing their antimutagenicity potential. Our results are supported by the fact that this product showed no mutagenic activity in the previous studies $[2,23]$.

The most carcinogens are inactive when present in the environment, on entering the system, they are converted into active metabolites by the carcinogen-metabolizing enzymes, further the protocol have improvised a method for detecting chemicals which are potential human carcinogens or mutagens by adding homogenates of rat liver directly to the Petri plates thus incorporating an important aspect of mammalian metabolism into the in vitro test $[2,24]$. In this study, antimutagenicity of Liv52 was studied by adding homogenates of rat liver to the Petri plates along with the extracts to understand the important aspects of mammalian metabolism in the in vitro testing.

This, ayurvedic product may have better antioxidant activity endow with the ability to intercept the free radicals generated by cellular

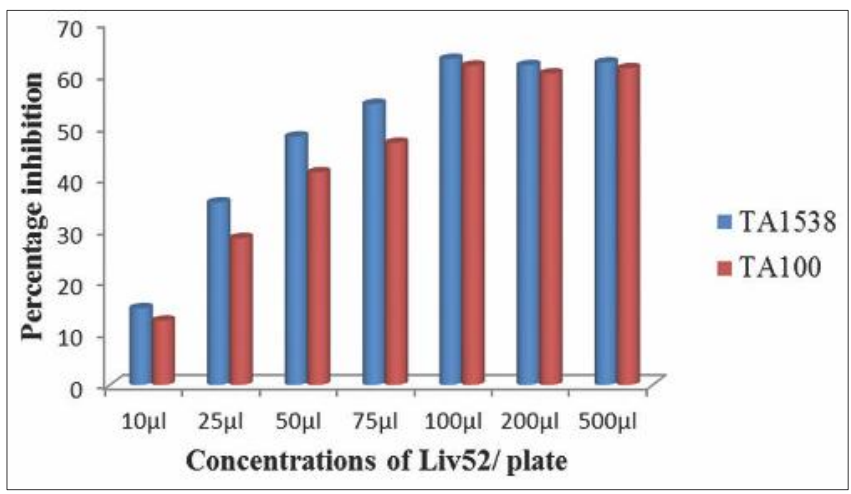

Fig. 1: Antimutagenicity of Liv52 against NPD induced mutagenesis in TA1538 and TA100 without $S 9$ mix by preincubation method. Results were expressed as the mean of 6 plates from two independent experiments with standard deviation Viable cell count was approximately 1-2 X $10^{9}$ cells $/ \mathrm{ml}$.

metabolism or exogenous sources, such as those resulting from the action of cyclophosphamide, thereby preventing their damage to lipids, amino acids, proteins, polyunsaturated fatty acid double bonds, and DNA bases [25]. The aqueous extracts of PM and BF can act directly on compounds that induce mutations in DNA, chemically or enzymatically inactivating them, may inhibit the metabolic activation of promutagenic agents, or may scavenge reactive molecules, as explained [23]. Thus, the considerable presence of antimutagen in Liv52 certainly contributed to their effective antimutagenic activity.

By this investigation, we clearly observed that the Liv52, which is routinely used in ayurvedic practice, have considerable antimutagenic activity, show no cytotoxic activity and may contribute to reducing the 


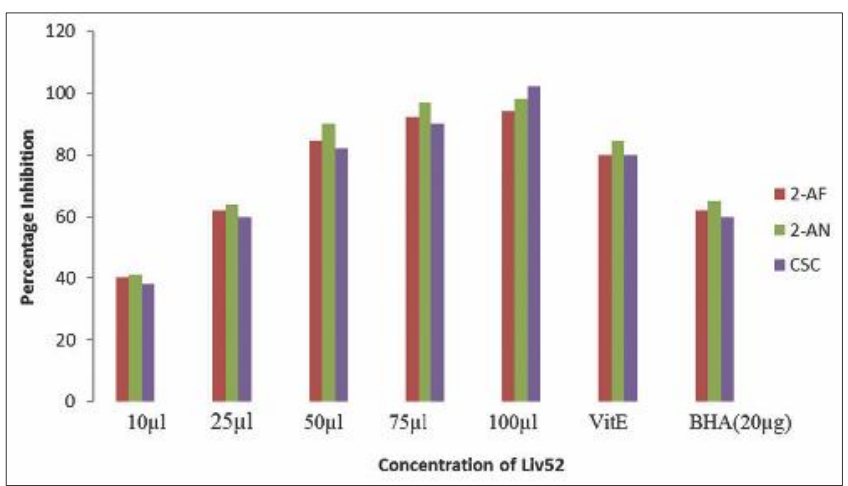

Fig. 2: Antimutagenicity of Liv52 against 2-AF, 2-AN and CSC induced mutagenesis in TA1538 with $S 9$ mix by preincubation method. Results were expressed as the mean of 6 plates from two independent experiments with standard deviation. Viable cell count was approximately $1-2 \times 10^{9}$ cells $/ \mathrm{ml}$

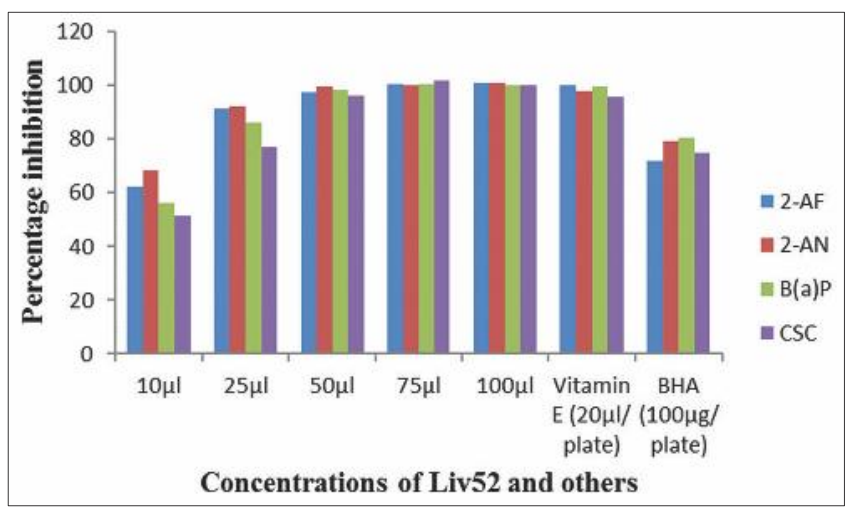

Fig. 3: Antimutagenicity of Liv52 against 2-AF, 2-AN, B(a)P and CSC induced mutagenesis in TA100 with $S 9$ mix by preincubation method. Results were expressed as the mean of 6 plates from two independent experiments with standard deviation. Viable cell count was approximately $1-2 \times 10^{9}$ cells $/ \mathrm{ml}$

chromosomal damage. Further, Liv52 having antimutagenic potential in it may play an important role in neutralization of various dietary mutagens and may act as a prophylactic agent against human ill-health attributable to mutation. Thus, the consumption of this ayurvedic product can bring added benefits and protection to individuals and also improving their quality of life and health. Further study in these aspects using some other in vitro and in vivo will test be warranted before finalizing the product as more successful.

CONCLUSION

Liv52 was found to be nonmutagenic in Salmonella assay, whereas manifested the antimutagenic potential both with and without metabolic activation. The enhanced antimutagenic activity of Liv52 on preincubation indicates that the antimutagenic factor(s) may be desmutagenic in nature. The exact mechanism by which Liv52 exerts antimutagenic potential is not known. The possibility of having diverse antimutagenic factors in Liv52 which act by different mechanisms are strongly indicated.

\section{ACKNOWLEDGMENT}

Authors would like to thank the KMC Mangalore for providing facilities for this work.

\section{REFERENCES}

1. Miyazawa M, Okuno Y, Fukuyama M, Nakamura S, Kosaka H. Antimutagenic activity of polymethoxyflavonoids from Citrus aurantium. J Agric Food Chem 1999;47(12):5239-44.

2. Prabhu N, Vigneshwari RS, Joseph PI. Antimutagenic effects of compounds obtained from Eclipta alba Linn against strains of Salmonella typhimurium. Int J Bioassays 2012;10(1):102-6.

3. Radhakrishna M, Hegde MJ. Antimutagenicity of Chyawanprash in Ames test. Int J Pharm Res Health Sci 2016;4(3):1188-94.

4. Ugur A, Saraç N, Çankal DA, Özle M. The antioxidant and antimutagenic activities of Ankaferd blood stopper,a natural hemostatic agent used in dentistry. Turk J Med Sci 2016;46(3):657-63.

5. Srividya AR, Dhanabal SP, Vishnuvarthan VJ. Mutagenicity/ antimutagenicity of plant extracts used in traditional medicine: A review. World J Pharm Res 2013;2(2):236-59.

6. Harman D. Aging: A theory based on free radical and radiation chemistry. J Gerontol 1956;11(3):298-300.

7. Harman D. Mutation, cancer, and ageing. Lancet 1961;1:200-1.

8. Kamiya H. Mutagenic potentials of damaged nucleic acids produced by reactive oxygen/nitrogen species: Approaches using synthetic oligonucleotides and nucleotides: Survey and summary. Nucleic Acids Res 2003;31(2):517-31.

9. Ramarathan N, Osawa NT, Namiki M, Tashiro T. Studies on the relationship between antioxidative activity of rice hull and germination ability of rice seeds. J Sci Food Agric 1986;37:719-26.

10. Fraga CG, Arias RF, Llesuy SF, Koch OR, Boveris A. Effect of vitamin $\mathrm{E}$ - and selenium-deficiency on rat liver chemiluminescence. Biochem J 1987;242:383-6.

11. Maurici D, Aardema M, Corvi R, Kleber M, Krul C, Laurent C, et al. Genotoxicty and mutagenicity. Altern Lab Anim 2005;33 Suppl 1:117-30.

12. Eastmond DA, Hartwig A, Anderson D, Anwar WA, Cimino MC, Dobrev I, et al. Mutagenicity testing for chemical risk assessment: Update of the WHO/IPCS harmonized scheme. Mutagenesis 2009;24(4):341-9.

13. Migliore L, Coppedè F. Genetic and environmental factors in cancer and neurodegenerative diseases. Mutat Res 2002;512(2-3):135-53.

14. Cooke MS, Evans MD, Dizdaroglu M, Lunec J. Oxidative DNA damage: Mechanisms, mutation, and disease. FASEB J 2003;17(10):1195-214.

15. Izzotti A, Saccà SC, Cartiglia C, De Flora S. Oxidative deoxyribonucleic acid damage in the eyes of glaucoma patients. Am J Med 2003;114(8):638-46.

16. Weakley SM, Jiang J, Kougias P, Lin PH, Yao Q, Brunicardi FC, et al. Role of somatic mutations in vascular disease formation. Expert Rev Mol Diagn 2010;10(2):173-85.

17. Sloczynska K, Powroznik B, Pekala E, Waszkielewicz AM. Antimutagenic compounds and their possible mechanisms of action. J Appl Genet 2014;55(2):273-85.

18. Bonneau D, Thybaud V, Melcion C, Bouhet F, Cordier A. Optimum associations of tester strains for maximum detection of mutagenic compounds in the Ames test. Mutat Res 1991;252(3):269-79.

19. Maron DM, Ames BN. Revised methods for the Salmonella mutagenicity test. Mutat Res 1983;113(3-4):173-215.

20. Ong T, Mukhtar M, Wolf CR, Zeiger E. Differential effects of cytochrome p450 inducers on promutagen activation capabilities and enzymatic activities of S9 from rat liver. J Environ Pathol Toxicol 1980;4(1):55-65.

21. Garner RC, Miller EC, Miller JA. Liver microsomal metabolism of aflatoxin B 1 to a reactive derivative toxic to Salmonella typhimurium TA 1530. Cancer Res 1972;32(10):2058-66.

22. Kada T, Morita K, Inoue T. Anti-mutagenic action of vegetable factor(s) on the mutagenic principle of tryptophan pyrolysate. Mutat Res 1978;53(3):351-3.

23. Kuroda Y, Jain AK, Tezuka H, Kada T. Antimutagenicity in cultured mammalian cells. Mutat Res 1992;267(2):201-9.

24. Geetha B, Santhy KS. Evaluation of antimutagenic activity of orange peel extract using Ames Salmonella microsome assay. Int J Life Sci Biotechnol Pharm Res 2013;2(3):466-71. 
25. Teixeira RO, Camparoto ML, Mantovani MS. Assessment of two medicinal plants, Psidium guajava L. and Achillea millefolium L, In vitro and in vivo assays. Genet Mol Biol 2003;26(4):551-5. 